\title{
Intra-articular glucocorticoid injections in patients with juvenile idiopathic arthritis in a Singapore hospital
}

Olivia Min Yi Leow ${ }^{1}$, MBBS, Lee Kean $\underline{\operatorname{Lim}}^{1}$, BN, AdvDip, Pei Ling $\underline{\mathrm{Oo}} \dot{i}^{1}$, MBBS, MRCPCH, Lynette Pei Chi Shek ${ }^{1,2}$, MBBS, MRCP, Elizabeth You Ning $\underline{\text { Ang }}^{1}$, MBBS, MRCPCH, Mary Beth $\underline{\text { Son }}^{1}$, MD

INTRODUCTION This study aimed to evaluate the efficacy and safety of intra-articular glucocorticoid (IAG) injections in our institution in children with juvenile idiopathic arthritis (JIA).

METHODS This is a retrospective assessment of IAG injections performed by the Department of Paediatrics, National University Hospital, Singapore, from October 2009 to October 2011. A total of 26 procedures were evaluated for efficacy, considering parameters such as clinical response, changes in systemic medication, length of time between repeat injections, safety, consent-taking, pre- and post-procedural advice, compliance with aseptic technique, and post-procedural complications.

RESULTS A total of 26 IAG injections of triamcinolone hexacetonide were administered over 17 occasions (i.e. patient encounters) to ten patients with JIA during the study period. After the injections, clinical scoring by a paediatric rheumatologist showed overall improvement by an average of 2.62 points out of 15 . Besides six patient encounters that had an increase in systemic medication on the day of the injection, five required an increase within six months post injection, two required no adjustments, and one resulted in a decrease in medications. In all, 21 injections did not require subsequent injections. The mean interval between repeat injections was 7.8 months. Cutaneous side effects were noted in three anatomically difficult joints. Medical documentation with regard to patient progress was found to be lacking.

CONCLUSION As per the recommendations of the American College of Rheumatology, we safely used IAG injections as the first-line therapy in our group of patients with oligoarticular JIA, and/or as an adjunct to systemic therapy in our patients with JIA.

Keywords: complications, efficacy, intra-articular injections, juvenile idiopathic arthritis, safety

\section{INTRODUCTION}

Juvenile idiopathic arthritis (JIA) is a group of disorders with onset in children below 16 years of age, clinically manifesting as arthritis of no known aetiology lasting at least six weeks. Despite being a diagnosis of exclusion, JIA is still the most common rheumatologic disease and cause of chronic arthritis in children worldwide, with an annual incidence ranging from 0.8 to $22.6 / 100,000$ children, and a prevalence ranging from 7 to 401/100,000. ${ }^{(1)}$ The International League of Associations for Rheumatology has published on a classification system for the different forms of JIA. ${ }^{(2)}$ In a 1998 Singaporean study, JIA accounted for $28.8 \%$ of all rheumatologic conditions, second to systemic lupus erythematosus (51.8\%). ${ }^{(3)}$ According to a registry established to study the epidemiological and disease features of JIA in Singapore, enthesitis-related JIA is predominant in the local population. ${ }^{(4)}$

According to the American College of Rheumatology (ACR) clinical guidelines, ${ }^{(5)}$ intra-articular glucocorticoids (IAGs) are recommended as the first-line therapy for oligoarticular JIA, except in cases of very mild oligoarticular JIA with low disease activity and no features of poor prognosis, where a twomonth trial of nonsteroidal anti-inflammatory drugs (NSAIDs) monotherapy may be administered. IAGs can also serve as an adjunct to systemic therapy in more severe forms of JIA to avoid increasing the dose of systemic agents, or for temporary patient relief while awaiting the effects of systemic agents. ${ }^{(6)}$

The benefits of IAGs are well described, including the rapid resolution of synovitis, provision of pain relief, aiding return to normal function, and reduction of complications of oligoarthritis such as leg length discrepancy. ${ }^{(7)}$ It has been found that the use of intra-articular triamcinolone hexacetonide (TH) injections with methotrexate is associated with longer remission periods. ${ }^{(8)}$ A study of 21 patients who underwent gadoliniumenhanced magnetic resonance imaging after IAG injections found improvements in inflammation and pannus formation, with no deleterious effects on articular cartilage. ${ }^{(9)} \mathrm{TH}$ is the preferred IAG, as several studies have demonstrated its use to result in longer remission periods than other glucocorticoid formulations. ${ }^{(10,11)}$

IAG injections must be administered aseptically to avoid complications such as septic arthritis, but the implementation of aseptic technique varies among doctors. In a 2003 survey involving orthopaedic surgeons, rheumatologists and general practitioners in the United Kingdom, it was found that $57.6 \%$ used alcohol swabs to prepare the injection area, with the remaining $42.4 \%$ using chlorhexidine or Betadine for knee

\footnotetext{
${ }^{1}$ Department of Paediatrics, Khoo Teck Puat-National University Children's Medical Institute, National University Hospital, ${ }^{2}$ Department of Paediatrics, Nationa University of Singapore, Singapore

Correspondence: Dr Mary Beth Son, Assistant in Medicine, Division of Immunology, Boston Children's Hospital, 300 Longwood Avenue, Boston, MA 02115, USA. marybethson@gmail.com
} 
injections. ${ }^{(12)}$ Only $16.3 \%$ of the surveyed doctors draped patients with sterile towels to isolate the injection area, only $32.5 \%$ consistently used sterile gloves while $53.4 \%$ did not use gloves at all, and over $90 \%$ changed needles to inject the IAG after drawing the steroid. ${ }^{(12)}$

Studies on the effects of postinjection rest (i.e. immobilisation, reduced activity or splinting) have been inconsistent. A 1994 study suggested that 24-hour bed rest was associated with longer periods of clinical response of the knee to IAG injections. ${ }^{(13)}$ However, other separate studies on 48-hour post-IAG immobilisation of the wrist and elbow joints showed no statistical difference in clinical response between immobilised joints and those that returned to normal activity. ${ }^{(14,15)}$ It has been suggested that weight-bearing joints benefit morefrom postinjection rest. ${ }^{(14)}$ Generally, 24-hour postinjection rest is recommended. ${ }^{(16)}$

Complications associated with IAG are uncommon and mainly localised. Of these, the most notable are cutaneous hypopigmentation and subcutaneous atrophy. The former is associated with repeated injections and darker skin, and though cutaneous hypopigmentation usually resolves in two months, it can also be permanent. The latter complication likely occurs due to leakage of the injected glucocorticoid compound into the skin, and is associated with injections of smaller joints and higher volumes and doses of glucocorticoids. ${ }^{(17)}$ The incidence of such cutaneous side effects was found to be $2 \%$ in one 1990 study, and $8.3 \%$ in another 2011 study. ${ }^{(18,19)}$ Other risks include intra-articular calcifications, which was found to occur in $4.9 \%$ in the same aforementioned 1990 study, ${ }^{(19)}$ periarticular calcifications, injury to surrounding structures and haemorrhage.

Septic arthritis, while a worrisome complication, is rare and estimated by one study to occur in $1 / 10,000$ injections, ${ }^{(20)}$ and 4.6/100,000 in another. ${ }^{(21)}$ An Icelandic study found a septic arthritis incidence of $0.037 \%$ in patients post arthrocentesis. ${ }^{(22)}$ Avascular necrosis (AVN) has been found to occur rarely in children with JIA receiving IAG. A retrospective study reported one case of hip necrosis out of 1,439 IAG injections. ${ }^{(23)}$ Another study reported three incidents of femoral head necrosis out of 67 IAG injections. However, these cases were found exclusively in the context of concurrent systemic corticosteroids, ${ }^{(24)}$ thereby making it difficult to strictly determine IAG as the cause of femoral head AVN.

Using a retrospective chart review, the present study examined the efficacy and safety of IAG injections in our population of patients with JIA treated at National University Hospital, Singapore.

\section{METHODS}

Assessment of the efficacy and safety of IAG injections was performed by means of extracting data from the medical records of patients, observing clinical consultations and IAG administration by a paediatric rheumatology nurse, and following up with patients on postinjection symptom resolution and complications. With regard to the efficacy of IAG, factors considered were postinjection clinical response, changes in systemic medication, and duration of interval between repeat injections.

Postinjection clinical response was assessed by a paediatric rheumatologist, scoring the following five domains: swelling, warmth, erythema, limitation of range of movement, and tenderness. Each domain is scored on a scale of $0-3$, with 0 being 'absent', 1 being 'mild', 2 being 'moderate' and 3 being 'severe'. The joints were scored over a total of 15 points, and the most recent scores before IAG injection were compared with the best scores within six months after IAG injection. A decrease in the score was deemed as an improvement, while an increase indicated poor clinical response. We noted cases where joints showed initial improvement (i.e. a decrease in scores) in the first three months after IAG injection, but which later worsened in the subsequent three months.

In the present study, changes in systemic medication referred to any increase or decrease in the dosage of systemic agents, and any change in the types of systemic agents used up to either six months post injection or up to the next encounter where an injection was administered. Duration of interval between repeat injections was measured in months.

With regard to the safety of IAG injections, factors considered were compliance with aseptic technique, incidence of postprocedural complications, informed consent, as well as adequacy of medical advice given about the procedure and postinjection care. Phone calls were made by a rheumatology nurse to all patients on post-procedural Day 1. Questions regarding range of movement, and extent of pain and swelling relief were asked. The nurse also enquired whether there were any post-procedural complications such as pain, swelling, fever and infection (evidenced by the presence of pus from the injection wound) or any other concerns or complaints the patient or caregiver may have had.

\section{RESULTS}

In all, 26 IAG injections of TH (Aristospan ${ }^{\circledast}$; Sandoz Inc, Princeton, $\mathrm{NJ}$, USA) at $20 \mathrm{mg} / \mathrm{mL}$ were administered on 17 occasions (i.e. patient encounters) to ten patients ( 6 male, 4 female) diagnosed with JIA within the period October 2009 to October 2011. The ages of the patients ranged from 4 to 19 years old, as documented at the time of their first documented injection during the study period. Table I details the patient demographics of our study cohort. Each of the 26 IAG injections was evaluated in terms of efficacy and safety.

Postinjection clinical response was analysed. Complete data with both pre- and postinjection scores was available for 21 of the 26 injections. Of these 21 injections, 8 were made to knee joints, 7 to ankle joints, 4 to wrist joints and 2 to foot joints. Of these 21 injected joints, 18 showed clinical improvement for a period of two months up to beyond six months post injection, with the exception of one injection, which lasted only one month due to a traumatic fall on the injected knee. Two joints post 
Table I. Patient demographics of the study cohort $(n=10)$.

\begin{tabular}{lc}
\hline Characteristic & No. of patients \\
\hline Gender & \\
Male & 6 \\
Female & 4 \\
Age at first injection (yrs) & \\
$4-7$ & 2 \\
$8-11$ & 3 \\
$12-15$ & 4 \\
$\geq 16$ & 1 \\
Ethnicity & \\
Chinese & 8 \\
Cambodian & 1 \\
Indonesian & 1 \\
Type of JIA & \\
Oligoarticular & \\
Polyarticular & 3 \\
RF-positive & \\
RF-negative & 2 \\
Systemic-onset & 1 \\
Enthesitis-related & 1 \\
\hline
\end{tabular}

JIA: juvenile idiopathic arthritis; RF: rheumatoid factor

injection showed no significant difference, and one deteriorated with worsening arthritis.

For the 21 injections, the mean change in the paediatric rheumatologist's score (out of a total of 15 points) was 2.62. Knee injections showed a mean score change of $-1.50,-2.71$ for ankle injections, -4.25 for wrists and -3.5 for foot joints. It should be noted that among the 18 joints that had shown improvement, 4 subsequently worsened in the next few months and required an increase in systemic medication. Three of these four joints belonged to patients with oligoarticular JIA who were not prescribed increased systemic medication on the day the IAG injection was administered. All the patients who received an increase in systemic medications on the day the joint injections were administered showed clinical improvement for at least a period of six months; this was seen in patients with non-oligoarticular JIA. Of the two non-oligoarticular JIA patients who were not given an increase in systemic medication on the same day as the administration of IAG, one showed a +5 -point deterioration in clinical scoring and the other showed no improvement in clinical scoring, with both eventually requiring escalation of systemic medication.

Follow-up data was available for 14 of the 17 patient encounters. Of these 14 encounters, changes in systemic medication were noted to be an indicator of clinical response in eight. The other six encounters involved increases in systemic medication on the same day of administration of the IAG injections, due to very active disease in multiple joints. Hence, any decrease in systemic medication in the six months post IAG injection could be a reflection of the titration of medications once the disease flare had subsided. Of the 8 patient encounters in which changes in systemic medication were an indicator of clinical response, there were $5(62.5 \%)$ with an increase in systemic medication in the six months after the last injection or up to the next encounter, $2(25 \%)$ involving no change within six months or up to the next injection, and $1(12.5 \%)$ involving a decrease in systemic medication. Of the five encounters with an increase in systemic medication in the six months after the last injection or up to the next encounter, there were involvements of an increase in dose or frequency of the existing diseasemodifying antirheumatic drugs $(n=2)$, a switch from etanercept to adalimumab ( $\mathrm{n}=1)$, addition of methotrexate to existing sulphasalazine and NSAID $(n=1)$, and addition of a sulphasalazine to an NSAID $(n=1)$. The case of a decrease in systemic medication involved a dosing reduction of sulphsalazine from twice- to once-a-day, and discontinuation of the NSAID. It should be noted that the two encounters involving no change, as well as the one encounter involving a decrease in systemic medication, all occurred in patients with oligoarticular JIA (Table II).

Of the 26 IAG injections administered, 21 were single injections (i.e. after which patients did not need to return for repeat injections) (Table III). Out of these 26 injections, 5 were repeat injections -3 were administered to separate knee joints, 1 to an ankle joint and 1 to a fifth metacarpophalangeal joint. The three knee injections had a mean interval of nine months between repeated injections, while the intervals between IAG injections to the ankle and fifth metacarpophalangeal joints were eight and four months, respectively.

Aseptic protocol was adhered to for all IAG injections. Sterile sets were used for each injection, the injection sites were cleaned with either iodine or chlorhexidine with $70 \%$ alcohol, and the fields were draped with a sterile towel. Sterile gloves were worn by the doctor performing the procedure, and care was taken to maintain sterility throughout the procedure. Verbal consent was obtained from all ten patients, complete with explanation of the procedure's purpose, risks, steps and expected outcome. All patients were given information leaflets during the consultation, which advised minimising activity for 24-48 hours after the procedure, taking the prescribed oral analgesia as needed for two to three days, keeping the injection wound clean and dry, using ice packs to reduce any inflammation of the injection site, looking out for red flags that may indicate infection and keeping to the arranged follow-up appointment, and also included information on how to contact the department for help if necessary.

In our study, we found that out of 22 injections with the necessary follow-up data, three were complicated by cutaneous side effects within six months of the injections. These injections were made to an ankle joint, a first metatarsophalangeal joint and a wrist joint. The wrist joint was noted to have circular subcutaneous atrophy of $1 \mathrm{~cm}$ in diameter at the injection site. The other two joints featured hypopigmented macules over the injection sites, which are relatively less disfiguring than subcutaneous atrophy. Otherwise, apart from one patient who had postinjection pain lasting for one day, no other negative complaints were received and no major complications such as septic arthritis or avascular necrosis arose. 
Table II. Changes in medication.

\begin{tabular}{|c|c|c|c|c|c|c|}
\hline $\begin{array}{l}\text { Patient } \\
\text { encounter }\end{array}$ & Patient & Diagnosis & $\begin{array}{l}\text { Joint } \\
\text { injected }\end{array}$ & Preinjection JIA medication & Postinjection JIA medication* & $\begin{array}{l}\text { Dosage change/ } \\
\text { indication }\end{array}$ \\
\hline 1 & A & $\begin{array}{l}\text { Enthesitis- } \\
\text { related arthritis }\end{array}$ & $\begin{array}{l}\text { Right } \\
\text { knee }\end{array}$ & $\begin{array}{l}\text { Subcutaneous etanercept } \\
25 \mathrm{mg} \text { every } 10-15 \text { days, } \\
\text { oral methotrexate } 10 \mathrm{mg} / \mathrm{wk}\end{array}$ & $\begin{array}{l}\text { Subcutaneous etanercept } \\
25 \mathrm{mg} \text { twice/wk, } \\
\text { oral methotrexate } 20 \mathrm{mg} / \mathrm{wk}\end{array}$ & $\begin{array}{l}\text { Increase/Treatment- } \\
\text { resistant right knee }\end{array}$ \\
\hline 2 & A & $\begin{array}{l}\text { Enthesitis- } \\
\text { related arthritis }\end{array}$ & $\begin{array}{l}\text { Right } \\
\text { knee }\end{array}$ & $\begin{array}{l}\text { Oral methotrexate } \\
20 \mathrm{mg} / \mathrm{wk} \text {, subcutaneous } \\
\text { etanercept } 25 \mathrm{mg} \text { twice/wk }\end{array}$ & $\begin{array}{l}\text { Subcutaneous adalimumab } \\
40 \mathrm{mg} \text { every } 3 \mathrm{wks} \text {, } \\
\text { oral methotrexate } 20 \mathrm{mg} / \mathrm{wk}\end{array}$ & $\begin{array}{l}\text { Increase/Knee } \\
\text { flared again after } \\
\text { fall on the knee }\end{array}$ \\
\hline 3 & C & $\begin{array}{l}\text { Polyarticular } \\
\text { JIA, RF-negative }\end{array}$ & Left knee & $\begin{array}{l}\text { Subcutaneous etanercept } \\
25 \mathrm{mg} \text { every } 2 \mathrm{wks} \text {, } \\
\text { oral diclofenac } 50 \mathrm{mg} \text { bd }\end{array}$ & $\begin{array}{l}\text { Subcutaneous etanercept } \\
25 \mathrm{mg} / \mathrm{wk}\end{array}$ & $\begin{array}{l}\text { Increase/ } \\
\text { No significant } \\
\text { postinjection } \\
\text { improvement }\end{array}$ \\
\hline 4 & B & $\begin{array}{l}\text { Oligoarticular } \\
\text { JIA }\end{array}$ & Left knee & $\begin{array}{l}\text { Oral sulphasalazine } \\
1 \mathrm{~g} \mathrm{bd} \text {, oral naproxen } \\
275 \mathrm{mg} \text { bd }\end{array}$ & $\begin{array}{l}\text { Oral methotrexate } \\
7.5 \mathrm{mg} / \mathrm{wk} \text {, } \\
\text { oral sulphasalazine } 1 \mathrm{~g} \mathrm{bd} \text {, } \\
\text { oral naproxen } 275 \mathrm{mg} \text { bd }\end{array}$ & $\begin{array}{l}\text { Increase/Response } \\
\text { to injection } \\
\text { started to wear } \\
\text { off after } 3 \mathrm{mths}\end{array}$ \\
\hline 5 & $\mathrm{D}$ & $\begin{array}{l}\text { Oligoarticular } \\
\text { JIA }\end{array}$ & $\begin{array}{l}\text { Right } \\
\text { ankle }\end{array}$ & Oral naproxen 275 mg bd & $\begin{array}{l}\text { Oral sulphasalazine } 1 \mathrm{~g} \mathrm{bd} \text {, } \\
\text { oral naproxen } 275 \mathrm{mg} \text { bd PRN }\end{array}$ & $\begin{array}{l}\text { Increase/Response } \\
\text { to injection wore } \\
\text { off after } 2 \text { mths }\end{array}$ \\
\hline 6 & B & $\begin{array}{l}\text { Oligoarticular } \\
\text { JIA }\end{array}$ & Left knee & $\begin{array}{l}\text { Oral methotrexate } \\
7.5 \mathrm{mg} / \mathrm{wk} \text {, oral } \\
\text { sulphasalazine } 1 \mathrm{~g} \mathrm{bd} \text {, } \\
\text { oral naproxen } 275 \mathrm{mg} \mathrm{bd}\end{array}$ & No change & No change/- \\
\hline 7 & D & $\begin{array}{l}\text { Oligoarticular } \\
\text { JIA }\end{array}$ & $\begin{array}{l}\text { Right } \\
\text { knee }\end{array}$ & Oral naproxen $275 \mathrm{mg}$ bd & No change & No change/- \\
\hline 8 & $\mathrm{D}$ & $\begin{array}{l}\text { Oligoarticular } \\
\text { JIA }\end{array}$ & $\begin{array}{l}\text { Right } \\
\text { knee } \\
\text { and right } \\
\text { ankle }\end{array}$ & $\begin{array}{l}\text { Oral sulphasalazine } 1 \mathrm{~g} \mathrm{bd} \text {, } \\
\text { oral naproxen } 275 \mathrm{mg} \text { bd PRN }\end{array}$ & Oral sulphasalazine $1 \mathrm{~g}$ om & $\begin{array}{l}\text { Decrease/Right } \\
\text { knee and ankle had } \\
\text { minimal symptoms }\end{array}$ \\
\hline
\end{tabular}

${ }^{*}$ At six months post injection or by the time of next injection. bd: twice a day; JIA: juvenile idiopathic arthritis; om: every morning; PRN: as necessary; RF: rheumatoid factor

All IAG injections performed were documented in the case notes, and the drug and dosage used were recorded either on the case notes or in an electronic patient database. Joint approaches for 12 out of 26 injections were not noted down.

\section{DISCUSSION}

IAG injections in patients with JIA in our institution were technically safe, with excellent compliance with aseptic technique and no major complications to date. The efficacy of IAG was demonstrated by our finding that all the joints showed a decrease in clinical scores post injection. However, this finding should be interpreted in the setting of frequent addition of systemic medications. Of the patient encounters that did not have an increase in their systemic medications on the day of IAG administration $(n=8)$, an increase in systemic medication within six months after the injections was necessary in 5 (62.5\%) (Table II). Two patients with oligoarticular JIA required an increase in systemic medication because their response to the IAG lasted less than four months. ACR's guidelines indicate that if the joint response to IAG lasts for less than four months in oligoarticular JIA, an increase in systemic medications should be considered. ${ }^{(25)}$ Two patients with enthesitis-related arthritis (ERA) required an increase in systemic medication due to resistant disease or flare following the IAG injection. In our cohort, one patient with seronegative polyarticular JIA required an increase
Table III. Injections to each type of joint.

\begin{tabular}{lccc}
\hline Type of joint & $\begin{array}{c}\text { No. of } \\
\text { injections }\end{array}$ & $\begin{array}{c}\text { No. of repeat } \\
\text { injections }\end{array}$ & $\begin{array}{c}\text { Average interval } \\
\text { between repeat } \\
\text { injections (mths) }\end{array}$ \\
\hline Knee & 9 & 3 & 9 \\
Hip & - & - & - \\
Ankle & 7 & 1 & 8 \\
Wrist & 4 & - & - \\
Hand joints & 3 & 1 & 4 \\
Foot joints & 3 & - & $\mathbf{7 . 8}$ \\
\hline \multicolumn{1}{r}{ Total } & $\mathbf{2 6}$ & $\mathbf{5}$ & \\
\hline
\end{tabular}

in frequency of etanercept because of the lack of significant postinjection improvement.

Out of the 26 injections, $21(80.8 \%)$ were single injections, which suggests satisfactory clinical response post IAG injection. The mean interval between repeat injections across all joints was fairly satisfactory at 7.8 months. It appears that injections to the knee joint fared the best, with the interval between repeat injections being an average of nine months in our patient group. While length of remission of symptoms in the joint or time to next required injection can be used to gauge response to IAG, ${ }^{(26)}$ there are many confounding factors such as the addition of systemic medications, the category of JIA, the duration of disease before the injection and injection accuracy. ${ }^{(17)} \mathrm{As}$ 
such, length of remission or time to next injection is likely a more reliable measurement of outcome when corroborated with other measures.

The findings of the present study are in line with the current knowledge, which state that while IAG injections play a role in symptomatic relief during acute flares and act as an adjunct to systemic therapy, disease-modifying antirheumatic drugs and anti-tumour necrosis factor- $\alpha$ agents are frequently required in JIA management. An exception to this would be patients with mild oligoarticular JIA, where IAG injections and/or NSAIDs may suffice. With regard to cutaneous changes post IAG injection, it is possible that joints with a more complex anatomy, and hence difficult access, and thinner subcutaneous tissue are predisposed to post-IAG cutaneous side effects. ${ }^{(17)}$ A study conducted on 38 children receiving ultrasonography-guided subtalar steroid injections found hypopigmentation in 53\% of the patients. ${ }^{(27)}$ This was thought to be due to leakage along the needle track resulting from overfilling of the joint space and use of larger-diameter needles. Precautions that can be taken to reduce postinjection hypopigmentation include the use of higher-gauge needles, good calibration of injection volume with joint space volume, immobilisation of the joint post injection, and administration of protective subcutaneous injection with normal saline during withdrawal of the injection needle so as to close off the track. Another study that focused on ultrasonography-guided IAG injections to 15 wrist joints found that 1 (4.7\%) developed postinjection subcutaneous atrophy. ${ }^{(28)}$

In the present study, medical documentation was inadequate. More attention should have been paid to this, as better documentation would facilitate closer monitoring of disease progression or remission. It should be noted that the necessity of written consent was not yet standardised for intra-articular injections at the time the injections in this study were performed. This was also the case for other procedures, such as lumbar punctures. However, it is now recognised that all such procedures, require proper written consent. Our centre's practice has over the past two years shifted from obtaining merely verbal consent to written consent without exception.

In conclusion, we found that patients with JIA treated at our institution safely underwent IAG injections, which are a useful first-line treatment and adjunct treatment in oligoarticular JIA and other types of JIA, respectively.

\section{REFERENCES}

1. Wu EY, Van Mater HA, Rabinovich CE. Juvenile Idiopathic Arthritis. In: Kliegman RM, Stanton BF, St. Geme III JW et al, eds. Nelson Textbook of Pediatrics, 19th ed. Philadelphia: Saunders, 2011: 829-39.

2. Petty RE, Southwood TR, Baum J, et al. Revision of the proposed classification criteria for juvenile idiopathic arthritis. J Rheumatol 1998; 25:1991-4.

3. See Y, Koh ET, Boey ML. One hundred and seventy cases of childhoodonset rheumatological disease in Singapore. Ann Acad Med Singapore 1998; 27:496-502.

4. Arkachaisri T. Pediatric rheumatology in Southeast Asia: insights from the Singapore experience. Curr Rheumatol Rep 2011; 13:117-22.

5. Beukelman T, Patkar NM, Saag KG, et al. American College of Rheumatology 2011 Recommendations for the Treatment of Juvenile Idiopathic Arthritis. Initiation and Safety Monitoring of Therapeutic Agents for the Treatment of Arthritis and Systemic Features. Clinician's guide.

6. See Y. Intra-synovial corticosteroid injections in juvenile chronic arthritis--a review. Ann Acad Med Singapore 1998; 27:105-11.

7. Sherry DD, Stein LD, Reed AM, Schanberg LE, Kredich DW. Prevention of leg length discrepancy in young children with pauciarticular juvenile rheumatoid arthritis by treatment with intraarticular steroids. Arthritis Rheum 1999; 42:2330-4.

8. Lepore L, Del Santo M, Malorgio C, et al. Treatment of juvenile idiopathic arthritis with intra-articular triamcinolone hexacetonide: evaluation of clinical effectiveness correlated with circulating ANA and T gamma/delta+ and B CD5+ lymphocyte populations of synovial fluid. Clin Exp Rheumatol 2002; 20:719-22.

9. Huppertz HI, Tschammler A, Horwitz AE, Schwab KO. Intraarticular corticosteroids for chronic arthritis in children: efficacy and effects on cartilage and growth. J Pediatr 1995; 127:317-21.

10. Honkanen VE, Rautonen JK, Pelkonen PM. Intra-articular glucocorticoids in early juvenile chronic arthritis. Acta Paediatr 1993; 82:1072-4.

11. Zulian F, Martini G, Gobber D, et al. Triamcinolone acetonide and hexacetonide intra-articular treatment of symmetrical joints in juvenile idiopathic arthritis: a double-blind trial. Rheumatology (Oxford) 2004; 43:1288-91.

12. Charalambous CP, Tryfonidis M, Sadiq S, Hirst P, Paul A. Septic arthritis following intra-articular steroid injection of the knee--a survey of current practice regarding antiseptic technique used during intra-articular steroid injection of the knee. Clin Rheumatol 2003; 22:386-90.

13. Chakravarty K, Pharoah PD, Scott DG. A randomized controlled study of post-injection rest following intra-articular steroid therapy for knee synovitis. Br J Rheumatol 1994; 33:464-8.

14. Weitoft T, Rönnblom L. Randomised controlled study of postinjection immobilisation after intra-articular glucocorticoid treatment for wrist synovitis. Ann Rheum Dis 2003; 62:1013-5.

15. Weitoft T, Forsberg C. Importance of immobilization after intraarticular glucocorticoid treatment for elbow synovitis: a randomized controlled study. Arthritis Care Res (Hoboken) 2010; 62:735-7.

16. Dernis E, Ruyssen-Witrand A, Mouterde G, et al. Use of glucocorticoids in rheumatoid arthritis - pratical modalities of glucocorticoid therapy: recommendations for clinical practice based on data from the literature and expert opinion. Joint Bone Spine 2010; 77:451-7.

17. Habib GS, Saliba W, Nashashibi M. Local effects of intra-articular corticosteroids. Clin Rheumatol 2010; 29:347-56.

18. Lanni S, Bertamino M, Consolaro A, et al. Outcome and predicting factors of single and multiple intra-articular corticosteroid injections in children with juvenile idiopathic arthritis. Rheumatology (Oxford) 2011; 50:1627-34.

19. Job-Deslandre C, Menkes CJ. Complications of intra-articular injections of triamcinolone hexacetonide in chronic arthritis in children. Clin Exp Rheumatol 1990; 8:413-6.

20. Hunter JA, Blyth TH. A risk-benefit assessment of intra-articular corticosteroids in rheumatic disorders. Drug Saf 1999; 21:353-65.

21. Pal B, Morris J. Perceived risks of joint infection following intra-articular corticosteroid injections: a survey of rheumatologists. Clin Rheumatol 1999; 18:264-5.

22. Geirsson AJ, Statkevicius S, Víkingsson A. Septic arthritis in Iceland 19902002: increasing incidence due to iatrogenic infections. Ann Rheum Dis 2008; 67:638-43.

23. Breit W, Frosch M, Meyer U, Heinecke A, Ganser G. A subgroup-specific evaluation of the efficacy of intraarticular triamcinolone hexacetonide in juvenile chronic arthritis. J Rheumatol 2000; 27:2696-702.

24. Neidel J, Boehnke M, Küster RM. The efficacy and safety of intraarticular corticosteroid therapy for coxitis in juvenile rheumatoid arthritis. Arthritis Rheum 2002; 46:1620-8.

25. Beukelman T, Patkar NM, Saag KG, et al. 2011 American College of Rheumatology recommendations for the treatment of juvenile idiopathic arthritis: initiation and safety monitoring of therapeutic agents for the treatment of arthritis and systemic features. Arthritis Care Res (Hoboken) 2011; 63:465-82.

26. Hetland ML, Østergaard M, Ejbjerg B, et al. Short- and long-term efficacy of intra-articular injections with betamethasone as part of a treat-to-target strategy in early rheumatoid arthritis: impact of joint area,repeated injections, MRI findings, anti-CCP, IgM-RF and CRP. Ann Rheum Dis 2012; 71:851-6.

27. Cahill AM, Cho SS, Baskin KM, et al. Benefit of fluoroscopically guided intraarticular, long-acting corticosteroid injection for subtalar arthritis in juvenile idiopathic arthritis. Pediatr Radiol 2007; 37:544-8.

28. Laurell L, Court-Payen M, Nielsen S, Zak M, Fasth A. Ultrasonography and color Doppler in juvenile idiopathic arthritis: diagnosis and follow-up of ultrasound-guided steroid injection in the wrist region. A descriptive interventional study. Pediatr Rheumatol Online J 2012; 10:11. 